\title{
Government's Control Countermeasures Against Environmental Pollution by Introducing Third-Party Constraints
}

\author{
Yanmin Zhao
}

School of Management, Wuhan University of Technology, Wuhan 430070, China; zymwhut@163.com

\author{
Nat. Env. \& Poll. Tech. \\ Website: www.neptjournal.com \\ Received: 22-02-2020 \\ Accepted: 15-04-2020 \\ Key Words: \\ Third-Party constraints; \\ Environmental pollution; \\ Game analysis; \\ Government governance
}

\begin{abstract}
With the rapid development of China's economy, environmental pollution becomes increasingly serious in recent years. The environmental governance model of "who pollutes, who governs" is that polluters handle pollutants following relevant laws and regulations under government supervision. Practice shows that this governance model has little effect. The pressure of social groups plays an important role in promoting compliance with laws and regulations and reducing corporate emissions. To improve the government's control of environmental pollution, third-party organizations as binding parties, mainly referring to the public, civil organizations, and the news media were introduced; a game model with government, sewage companies, and third-party organizations as participants was built. The results show that countermeasures against government environmental pollution are constrained third parties and effectively restrict the environmental pollution behaviour of sewage companies. This scenario alleviates the problem of information asymmetry between government and enterprises, reduces the cost of government supervision, and helps strengthen the governance of environmental pollution issues.
\end{abstract}

\section{INTRODUCTION}

With the rapid development of China's economy, environmental pollution becomes increasingly serious in recent years. Environmental pollution directly damages, negatively impacts the ecosystem and indirectly harms the ecosystem and the society. This indirect harm is greater and more difficult to eliminate than direct harm. The environmental impact derived from environmental pollution is lagging, and it is often difficult to detect or anticipate when pollution occurs. However, its occurrence means that environmental pollution has developed to a serious degree. The most direct and most easily felt effect of environmental pollution is the reduction of the quality of the human environment as well as the quality of human life, physical health, and production activities.

The "who pollutes, who governs" environmental governance model is that the polluters handle pollutants by relevant laws and regulations under government supervision. Practice shows that this type of governance has little effect. Pargal et al. (1996) proposed that pressure from social groups plays an important role in promoting compliance with laws and regulations and reducing corporate emissions. This study introduces third-party organizations as binding parties, mainly referring to the public, civil organizations, and the news media. It features a game model for participants to determine effective ways to restrict the behaviour of polluting enterprises and proposes government environmental pollution control measures under the constraints of third parties.
It not only provides a theoretical basis for the government's environmental pollution treatment, but it also has reference value for the research and implementation of government governance countermeasures in other fields such as education and medical care.

\section{PAST STUDIES}

Many scholars used game theory to study environmental pollution. Mäler et al. (1998) first applied game theory to the study of acid pollution in trans-administrative regions in Europe. He built models for up to 27 countries as participants and found that "unilateral payment" is the premise of cooperation among countries. Frisvold et al. (2000) used game theory to analyse the policy of the US-Mexico border water treatment project. Dungumaro et al. (2003) discussed the positive role and significance of public participation mechanism in environmental protection. Akihiko (2009) established a game model of the pollution behaviour of international duopoly countries in third countries. After a comparative analysis of two environmental policy tools, namely, emission tax and command-and-control regulation, he suggested that tough emissions policies increase the competitiveness of foreign companies. Besides, he pointed out that certain game strategies deviate the effects of environmental policies in third countries from their social optimal levels, and the games around emission taxes have a serious impact on the pollution situation and social welfare on levels of third countries. Kamwa (2012) believed that local governments have a 
great deal of enthusiasm to ignore environmental regulations and attract foreign investment by relaxing supervision of environmental issues in their jurisdictions, tax incentives, financial subsidies and other means, which ultimately worsen regional environmental quality. Hottenrott et al. (2015) believed that environmental protection policies based on fiscal decentralization incentivize enterprises to adopt advanced environmental protection technologies. The innovation of environmental protection technologies, in turn, reduces the costs of environmental damage and produces a crowding effect. Chinese scholars performed research in this area relatively late, mainly after 2000. Han et al. (2001) early on studied the prisoner's dilemma of pollution control in China's enterprises and explained the cause of the "tragedy of the commons" of environmental public goods use without government supervision from the perspective of game theory. Zhao et al. (2003) pointed out that information advantage and the absence of other constraints or incentives urge polluting enterprises and local governments to provide incomplete information to their superiors. Zhao et al. (2006) studied the regulatory game between the government and enterprises and believed that, in this game, the cost of pollution control of the company is positively related to the probability of government regulation; the probability of corporate pollution is positively related to the government's regulatory costs, and the impact on government reputation is negatively related to government fines for companies. From the perspective of game theory, Zang, et al. (2010) studied the issue of government environmental policymaking based on information mismatch. Li (2011) used the central and different local governments as participants to establish an "inter-government game" model of water pollution across administrative regions. Through analysis, the Nash equilibrium of the game of voluntary supply of public goods in the river basin was less than the optimal supply of Pareto conclusion. Based on statistical and econometric methods, game theory, and environmental economic theory, Wang (2013) comprehensively and thoroughly analysed the issues related to environmental pollution control and economic development. He discussed many questions about conspiracy issues in the regulation of "emissions tax" and the auctioneers of emission rights. Dong (2016) combined game theory and holistic governance theory to study the inter-governmental relations of urban agglomerations in China and explored strategies and methods for promoting coordinated governance of inter-governmental games in China's urban agglomerations. Yuan (2016) comprehensively applied modern economic research methods, such as public finance theory, fiscal decentralization theory, and game theory. He also used substantial statistical data to support and discuss the mismatch between the fiscal power and the power of local governments in environmental governance.
In summary, previous studies reveal the interactive relationship between the government and related entities like sewage companies and how the government takes countermeasures to control environmental pollution. However, in environmental pollution governance, the starting point of interest between polluting enterprises and the government is different. Hence, asymmetric information is widespread in the actual governance process. Therefore, the current study introduces third-party organizations as binding parties as well as constructs a game model with government, sewage enterprises, and third-party organizations as participants to effectively restrict the behaviour of sewage enterprises. This study also proposes government environmental pollution control measures under the constraints of third parties. Mobilizing third parties such as the public, non-governmental organizations, and the news media to assist government departments in monitoring the state of corporate emissions eases the problem of information asymmetry between the government and enterprises, reduces the cost of government supervision, and helps strengthen the governance of environmental pollution issues.

\section{METHODS}

\section{Research Hypothesis}

This study introduces a third-party organization as a binding party. However, in the pursuit of maximizing their respective interests, rent-seeking behaviour may occur between third-party organizations and sewage companies, conspiring to deceive government regulators to reduce pollution control costs and avoid economic punishment. With the government, sewage companies and third-party organizations as participants in environmental pollution incidents, a game model of environmental trilateral participation is constructed. The following are the main assumptions of this study. First, game participants are rational decision-makers. The government aims to maximize the overall social benefits, and third-party organizations and sewage companies aim to maximize their interests. Second, all three parties in the game of environmental pollution control introduced by the third party have a full understanding of the game structure and its own benefits and points, that is, a complete information static game. Third, the variables in the model are all greater than 0 .

The variables are set as follows:

(1) $p$ is the probability that a sewage company will rent-seeking a third-party organization, and 1-p is the probability that a sewage company will not rent-seeking a third-party organization.

(2) $q$ is the probability that a third-party organization will receive the rent-seeking business of a sewage company. 
(3) $r$ is the probability that the government department will supervise, and 1-r is the probability that the government department will not supervise.

(4) $C$ is the cost when the polluting enterprise discharges pollutants according to the standard; $\mu C$ is the income $(0<\mu<1)$ obtained by the polluting enterprise from rent-seeking to a third-party organization. $(1-\mu C)$ is the cost of rent-seeking and the gains from the third-party organization's acceptance of the rent-seeking enterprise. $\lambda \mu C$ is the penalty received by the sewage-seeking enterprise when its rent-seeking behaviour is discovered. $\lambda$ is a penalty factor, $\lambda>1$.

(5) $L$ is the penalty for the third organization receiving the sewage-seeking enterprise when rent-seeking is found.

(6) $M$ is the loss caused by the government department's failure to monitor rent-seeking behaviour between sewage companies and third-party organizations.

(7) $N$ is the cost of government supervision;

(8) $\theta$ is the supervisory capacity of the government department. Considering its asymmetric information, finding and not discovering rent-seeking behaviour between sewage companies and third-party organizations have two results, $0<\theta<1$.

Based on the above hypothesis, the following section establishes and analyses a game model in which the government, sewage companies, and third-party organizations participate.

\section{Game Income}

Let the probability of a rent-seeking behaviour between a sewage company and a third-party organization be $s$, then $s$ $=1-(1-p) \times(1-q)$, and the probability of a rent-seeking behaviour between a sewage company and a third-party organization is $1-s$. You can get the following benefits:

(1) When the sewage-seeking enterprise conducts rent-seeking behaviour with a third-party organization, consider the government's supervisory capacity $\theta$. When rent-seeking behaviour is found, then the benefits of the sewage-emitting enterprise, the third-party organization, and the government are as follows: $(1-\lambda) \mu C,(1-\mu) C-L, L+$ $\lambda \mu C-N-M$. When no rent-seeking behaviour is found, the three parties' returns are as follows: $\mu C,(1-\mu) C,-N-M$. If the government does not participate in the supervision, then the sewage company, the benefits of the tripartite organization, and the government are as follows: $\mu C,(1-\mu) C,-M$.

(2) When polluting enterprises and third-party organizations do not conduct rent-seeking behaviours and if the government participates in supervision, then the revenues of the polluting enterprises, third-party organizations, and government are as follows: $0,0,-N$. If the government does not participate in supervision, all three parties' returns are 0 .

Based on the above analysis, the game return matrix with the participation of sewage companies, third-party organizations, and the government can be obtained, as shown in Table 1.

\section{Model Solving}

According to Table 1, given the value of s, the expected returns from government participation in supervision and non-regulation are as follows:

$$
\begin{array}{r}
E_{1}=(L+\lambda \mu C-M-N) \theta s+(-M-N)(1-\theta) s+(-N) \theta(1-s) \\
+(-N)(1-\theta)(1-s) \\
E_{2}=(-M) s+0 \times(1-s)
\end{array}
$$

When the expected return from government participation in supervision and the expected return from non-regulation are equal, a game equilibrium state can be reached, that is, $E_{1}=E_{2}$. Then

$$
s^{*}=\frac{N}{\theta(L+\lambda \mu C)}
$$

At this time, $\mathrm{s}^{*}$ is the Nash equilibrium solution of the

\begin{tabular}{|c|c|c|c|}
\hline \multirow{3}{*}{$\begin{array}{l}\text { Sewage companies and } \\
\text { third-party organizations }\end{array}$} & \multicolumn{3}{|c|}{ Government } \\
\hline & \multicolumn{2}{|c|}{ Participate in supervision (r) } & \multirow{2}{*}{ Not involved in supervision (1-r) } \\
\hline & Discover rent-seeking behaviour $(\theta)$ & No rent-seeking behaviour discovery $(1-\theta)$ & \\
\hline Rent-seeking (s) & $\begin{array}{l}(1-\lambda) \mu C \\
(1-\mu) C-L, \\
L+\lambda \mu C-\mathrm{N}-M\end{array}$ & $\begin{array}{l}\mu C, \\
(1-\mu) C, \\
-N-M\end{array}$ & $\begin{array}{l}\mu C, \\
(1-\mu) C, \\
-M\end{array}$ \\
\hline No rent-seeking (1-s) & $\begin{array}{l}0 \\
0 \\
-N\end{array}$ & $\begin{array}{l}0 \\
0 \\
-N\end{array}$ & $\begin{array}{l}0, \\
0, \\
0\end{array}$ \\
\hline
\end{tabular}
rent-seeking behaviour of the sanitary sewage company and the third-party organization.

Table 1: Game income matrix with the participants. 
According to Table 1, given the $r$, the expected returns from government participation in supervision and non-regulation are as follows:

$$
\begin{gathered}
E_{1}=[(1-\lambda) \mu C] \theta r+\mu C(1-q) r+\mu C(1-r) \\
E_{2}=0
\end{gathered}
$$

When the expected return from sewage-seeking enterprises is equal to the expected return from non-rent-seeking behaviour, a game equilibrium state can be reached, that is $E_{1}=E_{2}$. Then

$$
r^{*}=\frac{1}{\theta \lambda}
$$

According to Table 1, given $r$, the expected returns of third-party organizations accepting rent-seeking and rejecting rent-seeking behaviour are as follows:

$$
\begin{aligned}
E_{1}= & {[(1-\mu) C-L] \theta r+(1-\mu) C(1-\theta) r } \\
& +(1-\mu) C(1-r) \\
E_{2}= & 0
\end{aligned}
$$

When the expected return from rent-seeking behaviour by a third-party organization is similar to the expected return from rejecting rent-seeking, a game equilibrium state is reached, that is, $E_{1}=E_{2}$. Then

$$
r^{*}=\frac{(1-\mu) C}{\theta L}
$$

In summary, in the case of determining the rent-seeking behaviour of polluting enterprises and third-party organizations and government participation in supervision, the Nash equilibrium solution of the three-party game can be divided into the following cases:

(1) Sewage companies and third-party organizations conduct rent-seeking behaviour with probability $\frac{N}{\theta(L+\lambda \mu C)}$, and the government participates in supervision with probability $\frac{1}{\theta \lambda}$.

(2) Pollution-discharging enterprises and third-party organizations conduct rent-seeking behaviour with probability $\frac{N}{\theta(L+\lambda \mu C)}$, and the government participates in supervision with probability $\frac{(1-\mu) C}{\theta L}$.

\section{RESULT ANALYSIS}

\section{Influencing Factors of Rent-Seeking Behaviour Between Sewage Companies and Third-Party Organizations}

Formula (3) shows that $s^{*}$ is an increasing function of $N$. The cost of government participation in supervision increases with $N$, decreasing the government's enthusiasm for participation, which increases the probability of sewage companies and third-party organizations to conduct rent-seeking. Meanwhile, $s^{*}$ is a decreasing function of $\lambda \mu C, L, \theta$. The government's penalties for sewage-seeking enterprises and third-party organizations participating in rent-seeking increase with $\lambda \mu C$ and $L$. These reduce the probability of rent-seeking companies and third-party organizations to conduct rent-seeking. The increase in regulatory capacity also reduces the probability of rent-seeking by polluting companies and third-party organizations.

$\lambda \mu C$ is the government's penalties for polluting enterprises that conduct rent-seeking behaviour, which is mainly controlled by $\lambda$. Therefore, reducing the rent-seeking behaviour of polluting enterprises and third-party organizations, that is, reducing $s^{*}$, can reduce the government's regulatory $\operatorname{cost} N$, improve the government's regulatory capacity $\theta$, and increase penalties $\lambda$ and $L$.

\section{Influencing Factors of the Efficiency of Government Participation in Supervision}

Formula (6) shows that the government takes polluting enterprises as the main regulatory object at this time, and $r^{*}$ is the decreasing function of $\theta$ and $\lambda$. Therefore, we should start from the supervision efficiency and reduce the supervision probability $r^{*}$ to improve the supervision efficiency. Therefore, government supervision efficiency is an increasing function of $\theta$ and $\lambda$. The government's regulatory capacity and the punishment of polluting enterprises that conduct rent-seeking behaviour increase with $\theta$ and $\lambda$. Hence, the efficiency of government participation in supervision increases.

As shown in Formula (9), the government regards third-party organizations as the main regulatory object, where $r^{*}$ is an increasing function of $(1-\mu) C$ and a decreasing function of $\theta$ and $L$. Besides, the higher the probability of government participation in supervision, the greater the cost of supervision is. Therefore, we should reduce the supervision probability $r$ to improve supervision efficiency. Therefore, the government's supervision efficiency is a reduction function of $(1-\mu) C$, which is the increasing function of $\theta$ and $L$. The cost of sewage-seeking companies' rent-seeking to third-party organizations and the benefits of third-party organizations' acceptance of rent-seeking increase with $(1-\mu) C$. Thus, the efficiency of government participation in supervision is reduced. The government's regulatory capacity and the punishment of third-party organizations increase with parameters $\theta$ and $L$. Hence, the efficiency of government participation in supervision increases. Therefore, reducing the probability $r^{*}$ of government participation in 
supervision and improving supervision efficiency can reduce the cost of sewage-seeking companies' rent-seeking to third-party organizations and the benefits $(1-\mu) C$ obtained by the third-party organizations that accept sewage-seeking companies' rent-seeking. Thus, the supervision capacity coefficient $\theta$ and the punishment $L$ of third-party organizations that accept the rent-seeking enterprises of pollutant discharge enterprises must be increased.

\section{PRACTICAL COUNTERMEASURES}

The above analysis results show that the government can reduce the probability of rent-seeking behaviour of polluting enterprises and third-party organizations in the process of polluting by formulating effective environmental pollution control measures and protecting the lives and health of the people.

\section{Reduce Regulatory Costs and Improve Regulatory Capacity}

The probability of a sewage-seeking enterprise's rent-seeking behaviour is directly proportional to the cost of government supervision and inversely proportional to the ability to supervise it. Therefore, the government should reduce the cost of supervision and improve its supervision capacity. It should also streamline its supervision institutions and curb the trend of further expansion of supervision institutions and the increase in the number of supervisors. Furthermore, the government should establish a lean unit-wide regulatory agency, uniformly formulate unit-wide regulatory rules and guidelines, give full play to the role of synergy, and transform each into time-consuming discrete supervision to cooperate with a coordinated and orderly integrated supervision. Implement a comprehensive and sustainable monitoring process to form a closed supervision system.

\section{Increase Punishment and Reduce Pollution Emissions}

The probability of a sewage-seeking enterprise's rent-seeking behaviour is inversely proportional to the penalties of the sewage-seeking enterprise and the third-party organization. Therefore, the government should increase penalties for polluting enterprises and third-party organizations that conduct rent-seeking behaviours. Once pollutant discharge enterprises find rent-seeking behaviour, they should immediately request rectification within a time limit or directly withdraw from the market and impose a large fine. Hence, they feel that the gain from rent-seeking behaviour is less than fine. Third-party organizations should formulate sound laws and regulations to regulate their behaviour, vigorously exert their restrictive role, promote the compliance of pollutant discharge enterprises with relevant laws and regulations, and reduce corporate emissions.

\section{Develop Incentives to Encourage Pollution Control}

In addition to the above penalties, the government can also develop incentives to reduce the probability of environmental pollution incidents. Pollution-discharging enterprises with lower-than-standard emissions and strictly monitored third-party organizations are given certain incentives to continue to treat pollution at high standards. Increase investment in environmental protection, support and guide capable environmental service organizations to participate in environmental pollution treatment, and grant subsidies and incentives to eligible third-party organization projects.

\section{CONCLUSION}

The environmental governance model of "who pollutes, who governs" is that polluters handle pollutants by relevant laws and regulations under government supervision. Practice shows that this governance model has little effect. This study introduces third-party organizations as binding parties, mainly referring to the public, civil organizations, and the news media. A game model with government, sewage companies, and third-party organizations as participants was built. The conclusions are obtained that the countermeasures against government environmental pollution under the constraints of third parties effectively restrict the behaviour of sewage companies. This study only uses the static game model, and the dynamic game analysis among the government, sewage companies and third-party organizations is the future research direction

\section{REFERENCES}

Akihiko, Y. 2009. Global environment and dynamic games of environment policy in an international duopoly. Journal of Economics, 97(2): 121-140.

Dong. S.J. 2016. Research on the overall governance of inter-government games in urban agglomerations. Changsha: Doctoral Dissertation of Hunan University, China.

Dungumaro, W. and Madulu, F. 2003. Public participation in integrate water resources management: The case of Tanzania. Physics and Chemistry of the Earth, 28: 1009-1014.

Frisvold, B. and Caswell, F. 2000. Transboundary water management game-theoretic lessons for projects on the US-Mexico border. Agricultural Economics, 24: 101-111.

Han, G.F. and Ma, N.X. 2001. A game analysis of inefficiency of environmental protection. Ecological Economy, 6: 19-22.

Hottenrott, H. and Rexhäuser, S. 2015. Policy-induced environmental technology and inventive efforts: Is there a crowding out? Industry and Innovation, 22(5): 375-401.

Kamwa, E. 2012. Tax competition and determination of the quality of public goods. Journal of Applied Microbiology, 112(1): 90-98.

$\mathrm{Li}, \mathrm{S} .2011$. Research on inter-government game of water pollution across administrative regions. Changsha: Doctoral Dissertation of Hunan University, China.

Mäler, K.G. and De Zeeuw, A. 1998. The acid rain differential game. Environmental and Resource Economics, 12(2): 167-184. 
Pargal. S. and Wheeler, D. 1996. Informal regulation of industrial pollution in developing countries: Evidence from Indonesia. Journal of Political Economy, 104(6): 1314-1327.

Wang, B. 2013. Game study on environmental pollution control and regulation. Beijing: Doctoral Dissertation of Capital University of Economics and Business, China.

Yuan, H.P. 2016. Research on local government's environmental pollution control under fiscal decentralization. Beijing: Doctoral Dissertation of Capital University of Economics and Business, China.
Zang, C.Q., Liu, Y. and Wang, L. 2010. The design of the policies of the environmental regulation under the condition of information asymmetry: Based on the perspective of game theory. Finance \& Economics, 5: 63-69.

Zhao, H.M. and Sun, M.Q. 2006. Game analysis of environmental pollution control in Yangtze River Delta. Environment and Sustainable Development, 5: 36-38.

Zhao, L.J. and Li, H.Z. 2003. Study on countermeasures for transboundary water pollution dissension of the river valley. China Population, Resources and Environment, 6: 52-57. 